\title{
Anti-Patterns for an Industrial PhD in the Field of ICT
}

\author{
Jaakkola, Hannu
}

IEEE

2020-12

Jaakkola , H , Mikkonen , T \& Systä , K 2020 , Anti-Patterns for an Industrial PhD in the Field of ICT . in 2020 IEEE Frontiers in Education Conference (FIE) . IEEE , IEEE Frontiers in Education Conference, Uppsala , Sweden , 21/10/2020 . https://doi.org/10.1109/FIE44824.2020.9273826

http://hdl.handle.net/10138/322901

https://doi.org/10.1109/FIE44824.2020.9273826

other

Downloaded from Helda, University of Helsinki institutional repository.

This is an electronic reprint of the original article.

This reprint may differ from the original in pagination and typographic detail.

Please cite the original version. 


\section{Anti-Patterns for an Industrial PhD in the Field of ICT}

\author{
Hannu Jaakkola \\ Computing Sciences \\ Tampere University \\ Pori, Finland \\ hannu.jaakkola@iki.fi \\ ORCID: 0000-0003-0188-7507
}

\author{
Tommi Mikkonen \\ Department of Computer Science \\ University of Helsinki \\ Helsinki, Finland \\ tommi.mikkonen@helsinki.fi \\ ORCID: 0000-0002-8540-9918
}

\author{
Kari Systä \\ Computing Sciences \\ Tampere University \\ Tampere, Finland \\ kari.systa@tuni.fi, \\ ORCID: 0000-0001-7371-0773
}

\begin{abstract}
PhD programmes run by universities are planned for the needs of full-time students who have funding for the study period and an opportunity to work full time as a member of the academic community. This approach aims at following the optimal way to the goals set by the State and the university for these studies - young students, immediate continuation after MSc graduation, with membership in the university's PhD programme ensuring progress. We call these students "administrative optimal" PhDs. However, universities also have a number of postgraduate students that work in industry. These students work full time, have significant and useful experience from practice, but have more limited resources to use for $\mathrm{PhD}$ related activities. This paper reports on the challenges related to PhD students working in industry based on experiences from the field of ICT; the root cause of which is the missing support provided by the university, which focuses on "administrative optimal" students in their PhD programmes. The paper focuses on ICT field, because it is our experience base. We believe that in ICT area it is more common to work simultaneously to studies. This fits especially in MSc studies in Finland, but the same tradition continues even in PhD level.The studies of industrial students typically need twice the time and encounter a variety of problems having their roots in the mental, practical and motivational side. We list the challenges and handle them in a structured way in the form of anti-patterns. To provide a context for our findings we have included a discussion related to general aspects of $\mathrm{PhD}$ studies in the paper. The aim of the paper is to open up the discussion about this important topic and report our summarised "close to one hundred years" of experience in mentoring and supervising PhD students.
\end{abstract}

Keywords-PhD studies, supervising, motivation, PhD process

\section{INTRODUCTION}

Postgraduate studies are an essential part of university activities. In Finland, it is also an important source of public (government) funding, since the number of $\mathrm{PhD}$ graduates affects the amount of funding. The idealistic and optimal way to organize $\mathrm{PhD}$ studies is based on the idea that the $\mathrm{PhD}$ student continues towards the higher degree straight after their master's degree. From an administrative point of view, the optimal path consists of a three-four year study plan in the role of a researcher conducting work in the university, funded by the university / a grant, and without any significant other duties rather those progressing towards the $\mathrm{PhD}$ degree. Motivation factors may vary, but in most cases, they come from an opportunity to continue their earlier work (MSc thesis), professor push, or the student's own academic interest in solving a complex problem or a general interest in being awarded a doctoral degree. Quite often the motivation is a combination of these. From the university (administrative) point of view fast entrance, after completing an MSc, is productive. This kind "administrative optimal PhD student" is under 30 years old and motivated to conduct a $\mathrm{PhD}$ in a short time. They only have experience of academic work, which is a disadvantage from one point of view, but on the other hand it helps to avoid any distraction from the completion of the doctoral thesis. The path may continue in an academic environment as a post-doc researcher or a teacher - still without work experience from industry.

Practice has proven to be different from this ideal of the administrative optimal student. Only a few PhD students have the opportunity and funding to fully concentrate on research work and the related doctoral studies. In most cases, even when the work is done in a university, funding comes from a variety of research projects. These dominate the goal setting of the work instead of the students' individual needs. In the best case the project duration is long enough to enable longterm (three or four years) research work towards the same goal. In most cases, however, the projects have a wide spectrum of goals ranging from industry-oriented and applied to academic research. Furthermore, the goal of life-long learning proposes that further studies can be taken at almost any point in professional life [4]. In such situations, it is fairly difficult to follow the optimal $\mathrm{PhD}$ path based on a research plan with a well-structured research problem and the ability to partition it into research outcomes - publications (in an articlebased thesis) or the structure of a monograph.

A $\mathrm{PhD}$ has also become an attractive option for practitioners - experts working full time in industry. A typical "industrial PhD student" in the field of ICT works in the consulting business or on demanding product or process development tasks. These kinds of $\mathrm{PhD}$ students typically do not share the same mindset as students who pursue their career straight after a masters'degree. Hence, their $\mathrm{PhD}$ programme is far from administrative optimal, as their opportunity to concentrate on academic research work is varying and limited, which means a longer time to finish their studies. They usually apply for the $\mathrm{PhD}$ program after several years of work experience and start their studies at an older age (a wide variation exists), at which the administrative optimal students usually finish. The motivation factors to start PhD studies are heterogenous - these will be discussed later in this paper. Because the research work is done simultaneously with work in industry, the duration of the studies is double or more than the "recommended standard". An additional problem is related to the $\mathrm{PhD}$ studies (courses), which are implemented according to the needs of full-time researchers working in the academic environment. There may also be some "threshold" 
type of requirements to obtain the official status of postgraduate student in the university. Even these are designed for the needs of full-time researchers. Finally, performance indicators of universities may also lead to universities applying rules that make the industrial $\mathrm{PhD}$ process difficult. The duration of doctoral studies and graduation age are examples of such metrics.

The archetypes mentioned above - administrative optimal and industry PhD students - are described in Table I below. In practice, there are various "intermediate" cases between the ends of the continuum. These include researchers working on different research projects and teachers conducting research work in academic organizations; researchers in research institutes; students with an external grant who are conducting independent research work.

TABLE I. TWO ARCHETYPES OF PHD STUDENTS: THE ADMINISTRATIVE OPTIMAL AND THE INDUSTRY PHD.

\begin{tabular}{|l|l|}
\hline Administrative optimal PhD & Industry PhD \\
\hline $\begin{array}{l}\text { Young, continuing to } \\
\text { postgraduate studies directly } \\
\text { after master's degree. }\end{array}$ & $\begin{array}{l}\text { Has experience in the real study } \\
\text { context. }\end{array}$ \\
\hline $\begin{array}{l}\text { Full time researcher working in } \\
\text { an academic organization. }\end{array}$ & $\begin{array}{l}\text { Shares time between main work } \\
\text { duties and research. }\end{array}$ \\
\hline $\begin{array}{l}\text { Works under the close control of } \\
\text { the supervising professor(s). }\end{array}$ & $\begin{array}{l}\text { Has a distant relationship to the } \\
\text { university and the supervisor. }\end{array}$ \\
\hline $\begin{array}{l}\text { Has full support of the processes } \\
\text { related to the PhD programme. }\end{array}$ & $\begin{array}{l}\text { Has limited (or negative) support } \\
\text { provided by the processes related to } \\
\text { the PhD programme. }\end{array}$ \\
\hline $\begin{array}{l}\text { Has little or no experience in } \\
\text { industry or practical work. }\end{array}$ & $\begin{array}{l}\text { Brings work experience to the } \\
\text { research work, and enriches academic } \\
\text { research in a significant way. }\end{array}$ \\
\hline
\end{tabular}

The goal of this paper is to report our experiences related to industry $\mathrm{PhD}$ students. This group of students has received little attention in planning and implementing $\mathrm{PhD}$ programmes, which concentrate on the needs of administrative optimal students and are only partially adapted to fulfil the needs of other students working in another academic or research context. While our experiences reported in this paper are from the field of ICT, based on preliminary discussions with professors in other fields, at least some of the experiences seem to be more widely applicable. These discussions are based on our multidisciplinary research projects with professsors from industrial engineering, business and management. We have also long experience in providing university level multidisciplinary continuing education for higher management and experts in industry and public organizations. Modules of such programs are on the responsibility of professors of different fields and provide a good forum for interaction both with professors and participants.

We will apply a structured presentation based on the idea of patterns and anti-patterns [5]. In software engineering, design patterns are used to implement certain positive properties in a software architecture. Anti-patterns, in contrast, represent bad quality solutions, which have some negative obstacles, and when recognized, must be mitigated by resolving actions. We have used the analogy, in which $P h D$ pattern represents the optimal $\mathrm{PhD}$ process, and $P h D$ anti-pattern a problematic $\mathrm{PhD}$ process. In software architecture anti-patterns (bad quality solutions) need corrective actions to avoid problems encountered; analogously in our paper the corrective actions are focused in avoiding and managing the problems encountered in industry $\mathrm{PhD}$ process. Our structured representation supports both recognition and correcting the problems.

In the following, a pattern represents the PhD process specified by the university considering its administrative needs in an optimal way - arrangements fulfilling the needs of an administrative optimal $\mathrm{PhD}$ student and the university administration. The (typical for an industry $\mathrm{PhD}$ student) are presented in the form of anti-patterns as a counterpoint to the pattern. In this paper we report anti-patterns typical for industry $\mathrm{PhD}$ students, based on our findings in practice. Our ultimate aim is to provide ideas on how to proceed beyond the obstacles documented by the anti-patterns.

Typical research strategies in ICT, especially in Software Engineering, apply the constructive research method [9] / design science approach [12], and the work is experiencebased and experimental $[1 ; 2]$. We reviewed some tens of $\mathrm{PhD}$ thesis supervised by us and the ones we have been acting as a reviewer or opponent in other universities. We found this true both in our own researcher community and in other universities (in Finland, some abroad)in the area of software engineering and information system sciences. In this kind of work the availability of empirical data and a test environment is beneficial - this comes from the company of the researcher. In contrast, a researcher has an internal view and access to company confidential data, processes and practices, which is beneficial in the validation of the research outcomes and can sometimes also provide concrete research problems. The disadvantage of the internal view is that it may lead to subjectivity and it may support the continuation of the company's bad practices. If the same work were done by an academic $\mathrm{PhD}$ researcher in a university (industry collaboration project), these problems would be avoided, but access to internal company matters would remain limited.

The rest of the paper is organized in the following way. In Section II, we present the background of the paper, first focusing on the general aspects of becoming a $\mathrm{PhD}$, and then the specifics of the Finnish system. Section III forms the core of the paper: we analyse the problems related to industry $\mathrm{PhDs}$ in the form of structured anti-patterns. In Section IV we have a look at/ examine some selected related studies. Finally, in Section V, we draw some final conclusions.

\section{HOW TO BECOME A PHD?}

\section{A. Elements of a PhD Programme}

Gaining a doctorate - what does it require? $\mathrm{PhD}$ applicants can barely see the big picture of the effort, at least not at the very beginning of the journey. In the view of the authors, the two key elements are the $\mathrm{PhD}$ thesis and $\mathrm{PhD}$ studies, which (at least in our case) are also expected to be fully planned by the candidate when applying for the $\mathrm{PhD}$ programme. Not all students see these as a balanced activity, but progress in one part faster than the other, or completely ignore the other dimension. Consequently, there are students that have finished all the necessary studies without making progress in their thesis, indicating that the student has a tendency towards the short-span approach - collecting credits from study-based outcomes is easier than engagement in long-span thesis writing. The opposite situation is also problematic: after defending the thesis, the missing PhD courses are not highly motivating activities. The purpose of studies is to support thesis writing; this aspect is not fully utilized if the studies are implemented as 'postmortem' activities. We also have seen 
students who have finally published their research and study plan after their defence. In our universities these artefacts are preconditions (set by the administration, nominated by the rules) to get the right to start as a $\mathrm{PhD}$ student. In practice, such plans are made for the communication between the supervisor and the student, but never confirmed in the "official process" of the study administration.

In addition to the research work (thesis) and studies that are usually seen as the main elements in the $\mathrm{PhD}$ process, two other elements exist: namely membership of the research community of the research area and the work context in industry. The main manifestation of membership in the research community are the publications, which may be parts of the thesis (article-based thesis) or just support the final work published as a monograph. Additional activities cover participation in conferences, workshops and other academic activities at local, national and international level. In general, membership of the research community prepares the candidate to become a researcher and to interact as a member of the community. For industry PhD students, this may cause practical problems because of the lack of funding and time for such activities.

The work context is the element mainly related to the industry PhD student only; to some extent it could be essential for students preparing their thesis on industry-oriented academic projects and for students acting as "free researchers". This raises the role of the company as part of the $\mathrm{PhD}$ process - either as support or as a source of weakness and problems.

$P h D$ studies may cover a variety of activities - courses, books and articles, etc. The role of studies is to support research outcomes and provide a deep (enough) understanding of the research methods relevant to the topic. Although the thesis must be based on solid research methods and prove knowledge of the relevant research, industry students easily prefer a pragmatic approach instead of finding the motivation to follow the strict rules of the relevant research methods.

Gaining a $\mathrm{PhD}$ is not only a mechanical achievement and process but also the growth and progress of the candidate. It is primarily a mental process that consists of the ability to conduct long-term research and studies; interaction and communication with a variety of stakeholders and the ability to work in collaboration with the supervisor. Technically, $\mathrm{PhD}$ studies, including all aspects, follow the principles of a project: a limited time, plan-driven, resource-driven, organized, managed and implemented in a systematic, preplanned way.

The $\mathrm{PhD}$ process suits different groups of $\mathrm{PhD}$ students in different ways. Above we have listed two stereotypes - the administrative optimal and the industry $\mathrm{PhD}$ student. To an increasing extent, universities aim to direct their full-time $\mathrm{PhD}$ students to a well-organized, school-like preplanned pipeline to get a fast pay-back on their "investment" in the form of $\mathrm{PhD}$ degrees. For an industry $\mathrm{PhD}$ student, in turn, such a preplanned, over-arching path is often missing. In the academic environment we find an additional group of $\mathrm{PhD}$ students academic Spin-off $\mathrm{PhD}$ students -researchers working full time in an academic environment as a teacher or project researcher. They have similar problems to industry $\mathrm{PhD}$ students in the use of resources (time is the most important of these), but benefit from full-time membership of the academic community. Del Carmen and Kollanus call the administrative optimal approach structured and the spin-off approach traditional. The traditional approach used to be the mainstream in the past in Finland too, but is becoming rarer and thus also the approaches characteristic of an industry $\mathrm{PhD}$ are becoming more difficult to implement because of the decreasing flexibility in academic work profiles.

\section{B. General Aspects}

The two main stakeholders of doctoral research are the supervisors and the surrounding research group. The main role of the supervisor is to guide and help the doctoral student during the process. This means helping in both methodology and topic. In addition, the supervisor often needs to provide coaching and mentoring throughout what is a long process. The supervisor may have his or her personal motivations, since the graduating $\mathrm{PhD}$ students are counted in CVs and $\mathrm{PhD}$ students are important resources for the supervisor's own research. One important aspect should be kept in mind - the supervisor is not a nice, kind friend of the candidate but a supervising, leading person and responsible, for their part, for the progress of the thesis project.

The research group provides the doctoral students with support. Other doctoral students can give peer support and students who have already graduated students can give senior advice. The support from the research group is not limited to content but is also important mentally during the long process. This resource is typically minimal or completely missing for industry $\mathrm{PhD}$ students, who are conducting their work in their normal working environment - in the company. The company is not able to provide support for the academic side of the thesis work but there is team support from the industrial side of the research problem, which may be valuable and missing for researchers in the academic environment.

The research topic, questions and goals are all important, and they should all be understood similarly by all stakeholders. Otherwise, the research may be disjointed or there might be communication problems. It is important that the research topic is interesting especially to the students but also to other stakeholders - especially the company in the case of the industry PhD student. Furthermore, the research topic should be valid, topical and challenging enough so that reporting in the research community becomes feasible. Too often we meet a situation in which the candidate expects the $\mathrm{PhD}$ thesis to be a second MSc thesis - i.e. a pragmatic construction without scientific challenge or novelty.

Here we come to importance of the research problem specification. Constructive work itself is not a problem - we have a lot of these in our own set of $\mathrm{PhDs}$, both completed and under progress. The key issue is that the candidate must be able to pinpoint what to do and see the difference between the academic and industrial goals. All of the problems may be $\mathrm{PhD}$ level problems, but how they are formulated is the key question. It is easy to pick up a hyped topic from industry but coming up with empiricism is more difficult. Conversely, the opposite problem is an overly wide topic, i.e. the inability to crystallize the research problem from its environment and to define a limited (manageable) scope for the work. Furthermore, it is important to have the ability to see the relationships of the research problem to the existing research work in the area and the ability to find a suitable research strategy (methods) to solve the problem, guide the research work and validate the results.

Doctoral research takes several years of hard work. For industry $\mathrm{PhD}$ students, it means being prepared to reserve 
evenings, weekends and holidays for the thesis work, even the ability to allocate time for it during office hours. Research work cannot be done in short time slots - there must be empty days in the calendar nominated for research. Thus, motivation - or even passion - is important. The student needs to be interested both in the topic and in getting the doctoral degree. The former is needed for good research results, the latter for staying focused through the long process. Typically, students have the willingness to study some problem area in depth that they have found in their working environment and the employer has a similar kind of motivation coming from the interests of the company. Unfortunately, the company's interests and roles tend to change faster than the student's. Likewise, another poor motivation factor is the use of $\mathrm{PhD}$ studies as a means for continuing (further) education in lifelong learning.

\section{Thesis in Industry - the Finnish Landscape}

In Finland it is rather common that master's theses are written while working in industry, in particular in the field of technology [7]. This has lowered the barrier between academia and industry during the studies, and it is not uncommon that employers offer special privileges to these students while they complete their studies. In fact, oftentimes the employers can even pinpoint a suitable supervisor for a student that is employed by the company. Moreover, in general, the relations between companies and research institutions are close in Finland. There are also state-supported collaborative research projects [8], which foster new ways of technology transfer [10]. In general, such agile collaboration between companies and research institutes has been found to enrich both parties [13]. We can also say that the seed for the growing interest in industry $\mathrm{PhD}$ degrees is sown by the prevalence of industry MScs; the practices learned in industry. MSc projects have lowered the threshold to start industry $\mathrm{PhD}$ research, quite often with the same supervisor as for the MSc thesis. Of course, the major difference is that the former is conducted in around one year, whereas the latter needs at least three to five years; this truth is often forgotten.

There are many reasons why this cooperation has been fostered. For the companies, the incentive has been the access to new employees with knowledge of new and emerging technologies. For universities, the cooperation has provided access to real-world problems that are waiting for novel solutions as well as partnership in research projects. Finally, and most importantly from the viewpoint of this paper, this cooperation has acted as a mechanism whereby students have had a natural opportunity to grow as specialists in their own field and gain recognition from both academia and the employing company. At best, this forms a powerful combination where all parties can gain various benefits.

Unfortunately, while in the short term it is easy to find common interests and motivation between research institutions, companies and students, when considering the situation in the time scale of a doctoral dissertation - three to five years - things are radically different. Not all software companies are ready to commit to anything with that time span upfront. When company plans change, the activities that were also supposed to serve the academic interests of employees aiming at the thesis may be cancelled. In fact, at a time when there have been major disruptions in the Finnish ICT landscape, the universities have witnessed numerous changes in thesis topics even at masters level, simply because the students no longer had the access to empirical data or the empirical data was never completed. Obviously, the situation is even more challenging for doctoral theses, which require an even longer time span. Consequently, a successful industry $\mathrm{PhD}$ student requires a topic that will remain relevant from both an academic and industrial perspective for an extended time span.

As the decisions are made by the companies, based on the companies' operational strategies, professors and other university supervisors have little say in these changes. The best that the supervisors can do is to mitigate the effect of the changes by counselling the students when they either partially retarget their theses to align with the company's new strategy or downplay or expand the scope of the theses so that enough empirical evidence is present.

This unique setup has resulted in a situation where there are numerous potential doctoral students working in industry, with good connections to research institutes. Moreover, many of these potential students are considering doctoral studies, as they are often supported by the companies they work for, at least in principle. Unfortunately, practice has shown that successful completion of a PhD in industry is much harder than the completion of a master's thesis.

\section{ANTI-PATTERN ANALYSIS OF INDUSTRY PHD STUDIES}

\section{A. Phase 1: Analysis}

The paper reports our experiences as supervisors of numerous $\mathrm{PhDs}$, both from industry and academia. The experience base covers mostly success stories (completed PhDs, which are not discussed in this paper), but unfortunately several failing (industry) PhDs, too. Our focus here is on PhDs that failed. A failed thesis, by our definition, covers theses that were never finished (suspended), are completed but are poor in quality, or have had significant problems during the $\mathrm{PhD}$ process in comparison to an average thesis. Although our focus is on industry $\mathrm{PhD}$ students, similar problems may appear with researchers in the academic environment, especially in the case of "spin-off PhDs". In other words, some of the phenomena are general - but may be more common with industry PhDs, since their access to peer support, supervision and university resources is often limited.

Our experiences come from Finnish universities, from the ICT industry, and from the field of software engineering (SE). The authors have also been working some periods abroad and in leading expert positions in industry, which has extended the view to the topic to cover international aspects and industry point of view. All the authors have worked in an environment where industry-academia collaboration has been active, and we have all participated in both MSc and $\mathrm{PhD}$ supervision of students in industry. However, we acknowledge that $\mathrm{PhD}$ programs are culture-sensitive, science-sensitive and that differences even exist between universities within a country. Traditions, funding principles, programme structure, funding elements etc. all vary. However, we believe that problems are similar also in other contexts, where industry $\mathrm{PhDs}$ are relevant and common.

To provide means for a systematic analysis of problems related to industry $\mathrm{PhDs}$ we have reported our findings in a structured (anti)pattern format. Our anti-patterns are described in Section IV. Our (anti)pattern structure includes the following components:

- Name of the pattern: Unique name used to identify the anti-pattern 
- Context: A context or situation giving the background to a problem.

- Problem: Description of the problem handled by the pattern.

- Symptoms: How this problem is seen in practice manifestation of the problem.

- Corrections: How to fix / avoid the situation (if possible) - corrective actions.

- Notes: Other notes related to the situation.

The pattern structure helps the readers to adopt the "lessons learned" in their own work context. The anti-pattern list is not complete - just a collection of recognized situations that have been experienced.

The way we have formed our anti-patterns consists of two phases. First, in phase 1, a list of anti-pattern candidates were collected as a result of a brainstorming session by the authors.

The series of free format brainstorming session were organized to collect anti-pattern candidates. In phase 1 (elicitation) these were first listed (including a short explanative text) and documented after a face-to-face meeting of the authors. Documentation of these results established a first baseline to our work, which was continued using a shared document. The work was continuing in remote mode using shared documents and some organized Teams meetings. After three iterations we met a penetration stage, in which no new ideas were appearing. Then (phase 2 - analysing) we started to group the candidates (in Teams meetings and in distributed work based on a shared document) and analyse them. We found a some similarities with different manifestations in our candidate anti-patterns. In phase 3 (prioritization and documantation) the anti-patterns that the authors considered the most profound were documented in accordance with the format above. In this phase the patterns were documented by one author, and then reviewed by the others. Final result was the ten anti-patterns documented in this paper.

\section{B. Phase 2: Industry PhD anti-patterns defined}

We started by listing the (sixteen) anti-patterns that have roots in our experiences of industry PhDs. We will deal with the findings first as a list to give an overview of the topic (below) and then by examining the selected anti-patterns in detail in subsection III.C. As mentioned earlier, industry students are not an enclave among $\mathrm{PhD}$ students; many of the anti-patterns fit other groups too, but they are more common and typical in this group. We have grouped some (five) anti-patterns to indicate different manifestations of the same phenomenon as another - "also known as" (aka) indicates this grouping. The anti-patterns are listed below (in alphabetical order):

1. Career change: Change from one discipline to other without understanding that a background in the new science is required.

2. Empiricism provider: The student becomes a co-author of (numerous) papers where company data plays a key role. However, he/she never assumes full responsibility over planning a research study, collecting data, or even authoring a paper. The professor uses the student's work as a case of his/her own research.

3. Escape pod aka Disappointment therapy: The student seeks for an escape from doing something else or from a certain situation. The symptoms include fragmented attention and using the thesis as an escape pod from other tasks every now and then, but without real focus.
4. External pressure aka Reversed motivation: Instead of personal interest the motivation comes from external sources, e.g. from the professional or employer's direction. The motivation to start as a $\mathrm{PhD}$ student comes from the supervising professor.

5. Reversed responsibilities: The student expects the professor, instructor and colleagues to produce results for him.

6. I know this best (at least better than you): Strong belief in one's own excellence, knowledge and skills. Underrating the expertise of the professor and experts of the field (if they disagree with the student).

7. Just-jump-in aka NIKE method: Lacking understanding about the basic principles of PhD studies, which should be planned and well-organized. A PhD student without a study and research plan. Nike method - "Just do it".

8. One trick pony: One good simple idea repeated, no new results produced or possible to produce. Too narrow a research idea.

9. Out-of-steam: This was harder than I expected. Underestimated expectations regarding the reality.

10. Performance anxiety aka Not leaving comfort zone: Yet another contribution - never-ending. The student is not willing to finish the work.

11. Research as a hobby aka Missing commitment to the company needs: The students sees the research work as a hobby without clear academic or practical motivation. A researcher works as a hobby researcher in a company, having just a personal motivation. Company support is missing.

The list gives examples of real situations based on our experiences. Continuing the collection would be enabled by collecting the findings of other colleagues. It would also be extremely interesting to extend the scope to cover universities in other countries. We have already mentioned above that university studies are culture-dependent: there are variations between countries, sciences and universities also inside a country. Our aim has been to give examples and open up - if interest can be found - wider discussion related to the topic.

\section{Phase 3: Forming Industry Anti-patterns}

Next, we elaborate six selected anti-patterns. In this context it is not justifiable to handle all the listed cases, nor is it possible because of the limited space available. These anti-patterns have been selected for more detailed discussion, because with all these anti-patterns there is a tendency where the $\mathrm{PhD}$ process starts in a promising fashion, but after the first successes, problems begin to manifest themselves. With other patterns, the problems in the research tend to surface at the beginning, and hence they are easier to deal with.

Empiricism provider: The Empiricism provider antipattern (Table II) is common for various topics in software engineering, where empirical evidence forms the core input for the research. Quite often the research work, initiated by a professor, needs empirical data to test the results or a platform to implement and test the results. Then, a student who works in the industry finds himself in a role where he provides empirical data to the rest of the research group but has little role in the research otherwise.

TABLE II. EMPIRICISM PROVIDER ANTI-PATTERN

Name of the pattern: Empiricism provider (2)

Context: The student works at a company, thus also providing easy access to empirical data for the research team at the 
university, which is valuable for several types of research. Furthermore, the student is socially talented, and well able to network with the academic research staff. The research questions and study plans come from the professor or university researchers.

Problem: The student becomes a co-author of numerous papers where company data plays a key role. However, the student never assumes full responsibility for planning a research study, collecting data, or even authoring a paper. Instead, the academic staff finds it too tempting to overly rely on data provided by the industry student, and does not give him/her an opportunity to mature at their own pace. The professor may amplify this by focusing on published papers, where company empiricism plays a key role. Hence, the student becomes a central figure in the team, but never takes full academic responsibility for anything, including, in particular, writing papers.

Symptoms: Increasing number of publications where various academic co-authors are the lead author, and the industry student is an additional author; several publications, but students are not able to write the thesis from their own contributions.

Corrective actions: One of the first publications is authored by the candidate alone, and only the professor provides help to avoid overly assisted publications.

Notes: This works fine until the time to compose the thesis comes; the student quickly gathers all the necessary articles for the thesis, but the introductory part turns out to be a major obstacle.

Escape pod: The Escape pod aka Disappointment therapy anti-pattern (Table III) has its roots in the dissatisfaction of candidates with the existing situation - they want to escape from it to something that provides the opportunity to gain feelings of satisfaction. The reasons for the dissatisfaction may be manifold - work, home, colleagues or just the feeling that they have not achieved enough in life. They have an internal need to show their validity to their (ex-) bosses, family etc., but this is not enough motivation for long-term research that calls for extended focus.

TABLE III. ESCAPE POD AKA DISAPPOINTMENT THERAPY ANTIPATTERN

\section{Name of the pattern: Escape Pod aka Disappointment therapy} (3)

Context: Daily work does not provide enough of a challenge or a research career is an unfulfilled dream, so the student goes to look for challenges from the research scene. However, the research ideas emerge from the student's own interest, and there is no connection to the research project in the university or the business goals of the company.

Problem: The student conducts research without any concrete goal that could be shared by other stakeholders. The employer ignores the research (sometimes because the student has selected a topic that does not match the employer's interests, on purpose) and the topic is outside the interest areas of the professor. Sometimes, students are not satisfied with their current working role and seek satisfaction from elsewhere.

Symptoms: Manuscripts without focus or clear goals. Research is not connected with related work. Shifting interest and going with the flow. No overall research questions have been defined.

Corrective Actions: Research methodology training is taken at the beginning. The topic and the professor are carefully selected instead of taking the lowest-hanging option. The first papers are written under the close supervision of the professor to keep the focus and goals clear.

Notes: This pattern is often connected with others, in particular 'I know it best'.
I know this best: The origins of the I know this best antipattern (Table IV) lie in the self-confidence of the $\mathrm{PhD}$ candidate. Usually, this anti-pattern takes place with students who have had a good, progressive career in the company, the position of an expert or (middle) manager; they are used to making decisions and have the "undisputable right to be right", based on their position. When they extend their operations to the research area, they have difficulties to adapt to the role of a journeyman and to accept guidance or critique from more experienced researchers and the supervisor. Rather, the student tends to overlook evidence that is not in line with his/her opinions.

\section{TABLE IV. I KNOW THIS BEST (AT LEAST BETTER THAN YOU)}

\section{Name of the pattern: I know this best (at least better than you)} (6) Context: The student has long experience in industry and has gained a good reputation for his/her engineering skills, strategic views and analytical abilities in the industrial context. Often, the student has been recognized as an expert in the organization and his/her opinions are often accepted without major criticism. The research results also seem to work in practice, based on industry opinion. However, in the academic context there is little merit, experience or evidence.

Problem: Students are so confident about the value and validity of the results that they are not motivated to work on the evidence that the scientific community requires. This leads to the situation where the student does not accept scientific peer feedback. Results from valid research sources are underrated if they do not support the ideas of the student. Students are reluctant to follow academic writing principles which are not typically used in industry reports, as well as reluctant to move away from their own research goal. The professor may exacerbate this development by not being determined enough at the beginning of the process. Furthermore, the professor might need the company to obtain funding and thus be reluctant to give the required feedback. Also, a company culture that does not encourage open and constructive criticism amplifies this anti-pattern. Poorly done peer review intensifies the situation, too. The student does not understand and does not have the motivation to learn the role of scientific principles and practices. Unlike young students in university, the research is not started with method training, but rather with trial and error on publication scale.

Symptoms: Disrespect of scientific research methods; opinionated experiments and research goals; overlooking of research results by other researchers; unvalidated claims.

Corrective actions: Methodology training is taken at the beginning. The professor is more involved in the first publications, ensuring that the papers will have clear enough focus.

Notes: If the attitude dominates the whole thesis process, the final result will be a poor quality thesis, which will have difficulties to become accepted. This leads to strong disagreement about the grade of the thesis between the candidate and opponents \& supervisor - maybe as far as making a complaint to the next body in the process.

One trick pony: The typical characteristic of the One trick pony anti-pattern (Table V) is to repeat one (usually the first) research idea over and over again. The student has difficulties to accept that the first, maybe very good and innovative, research result cannot be repeated in new articles and other outcomes.

TABLE V. ONE TRICK PONY ANTI-PATTERN

Name of the pattern: One trick pony (8) 
Context: The student is successful with the first publication and thinks that the continuation will be just as easy. In essence, this means the same idea (or its variant) is repeated in different publications and at different venues, and no new results emerge.

Problem: The employer or professor giving a good topic but only for the size of one paper is one natural cause of this pattern, or there is not enough supervision and guidance of the student. There is no overall plan for the thesis or publication plan; instead the student goes on to repeat the earlier success.

Symptoms: Good start and motivation, followed by huge disappointment as it turns out that the same results are no longer accepted for publication; in cases where different venues accept the same results all over again, there is a rapid publication pace but no new insights.

Corrective actions: Make an overall research and publication plan for the whole doctoral thesis before submitting the first papers. Over time, the plan may evolve, but it still gives a roadmap of things to study as well as providing evidence that the size of the topic is feasible for a doctoral thesis.

Notes: A variant of this pattern is that the student ends up writing numerous papers on different topics. While the root cause and actions are the same, a more appropriate name is the Reverse/Bottom up process.

Out-of-steam: The Out-of-steam anti-pattern (Table VI) relates to the expectations of the student at the beginning of their $\mathrm{PhD}$ studies. Underestimating the resource needs becomes a reality and the student finds himself facing reality - not enough time, slower progress than expected, and increasing problems to combine studies, work and family. All things combined, this leads to frustration towards the studies in general, which in turn can lead to the realization of other anti-patterns listed here.

\section{TABLE VI. OUT-OF-STEAM ANTI-PATTERN}

\section{Name of the pattern: Out-of-steam (9)}

Context: Even in the optimal case of the thesis taking 3-4 years, if the candidate works in industry it might take even longer to complete the studies. This is a long effort and many conditions may change during the work. During that time, industrial $\mathrm{PhD}$ candidates usually have breaks in progress, be it to take some distance from the thesis or due to changes in other aspects of life, and it is sometimes hard to return from these breaks.

Problem: The thesis is put on hold and no observable progress takes place. The employer or professor does not give long-lasting support or a "wake-up call" when it would be a good time to do so, and the student is left on his/her own.

Symptoms: No progress; lack of motivation; sometimes developing an interest in other things in life.

Corrective actions: The supervisor should organize coaching events. In addition, it is important to be realistic in the initial planning. The student should also remember to take holidays in the process.

Notes: The final end of the process would be that the researcher begins to underrate the significance of the research work, and the importance of the PhD degree.

Performance anxiety: The Performance anxiety aka Not leaving the comfort zone anti-pattern (Table VII) is often associated with researchers who aim at perfection (perfectionist). One more result is always needed, and the ability to end the work and to wrap it up in the form of a published dissertation is missing. In the background, there might be the need to leave the comfort zone of scientific writing of short outcomes (articles) and fear of public criticism related to the thesis.
TABLE VII. PERFORMANCE ANXIETY AKA NOT LEAVING THE COMFORT ZONE

Name of the pattern: Performance anxiety aka Not leaving the comfort zone (10)

Context: The student has numerous articles and has proven his/her abilities as a researcher, to the extent that it is clear that the contributions are well worth a doctorate. However, there is little interest in writing the introductory part of the thesis and graduating as a PhD.

Problem: The student does not see any benefit from graduation. Instead, continuing with conference papers offers a way forward to visit conferences and to maintain their established role as a senior researcher.

Symptoms: Gradually extending the scope of the thesis. Requiring yet one more paper in a compilation thesis.

Corrective actions: Clear scope definition with the supervisors and company representatives. Introduction of a bonus for graduation for the student as well.

Notes: This pattern is often connected with others, in particular 'Out of steam'.

The patterns above demonstrate the wide variety of problems related to $\mathrm{PhD}$ students regarding the progress of their studies towards the final degree. The relationship between patterns and students is many-to-many. We may have optimal students that progress without any problems, one student may exhibit a combination of several patterns, and of course one pattern may be seen in many students. In the case of industry PhD students, as seen in the Actions section of the patterns, many of the patterns would be avoided by systematic mentoring and coaching the student for a career as a researcher. In addition, the universities should adapt their $\mathrm{PhD}$ processes to provide support for different student archetypes.

\section{Phase 4: synthesis}

After listing and defining the most important anti-patterns, we next place the focus on the similarities, recommendations and corrective actions needed to avoid the problems reported. These are recommendations to the supervisor; we have selected the supervisor as the target, because in the antipattern analysis we noticed that the supervisor holds the key position. We divide our recommendations into three groups according to the phase of studies: prework before commitment, first steps to get started and execution. For the prework we recommend the following:

- The topic (and professor) is carefully selected instead of taking the lowest-hanging option available. The emphasis should be put on compatible motivations of company, supervisor and student. This is particularly related to the anti-patterns of 'escape pod', 'reversed responsibilities' and 'research as a hobby'.

- Organize a demotivational discussion between the supervisor and the candidate, to measure the real motivation of the candidate and inform him/her about all the stumbling blocks which may appear during the work period of several years; sleep on it for a night or two and take the final decision to start after that. The anti-patterns described in this paper could be used as discussion topics in these sessions, in particular for the 'one trick pony', 'out-of-steam', 'performance anxiety' and 'research as a hobby' anti-patterns.

- Make an overall research and publication plan for the whole doctoral thesis before submitting the first papers. Over time, the plan will usually evolve, but it still gives a 
roadmap of the topics to study as well as providing evidence that the size of the topic is feasible for a doctoral thesis. This research plan should be created and agreed as a collaborative effort between student, supervisor and company. The result should be a three-party commitment. Related anti-patterns are the 'one trick pony', 'out-ofsteam', 'performance anxiety' and 'just jump in'.

During the first steps, the recommendations we propose are as follows:

- Some research methodology training should be taken right at the beginning. Taking the "full set" may be unnecessary, but the core scientific principles should be discussed at the beginning of the process. There is a temptation to postpone this for industrial $\mathrm{PhD}$ students because they often work on rather "practical" topics. However, early learning of the principles may be even more important for industrial $\mathrm{PhD}$ students than academic ones, since the former work more independently from the supervisor than the latter. The related anti-patterns are ' $\mathrm{I}$ know this best' and 'one-trick pony'.

- The student should be given a suitable amount of independence in the first paper. Although the first papers are written under the close supervision of the professor to keep their focus and goals clear, the paper should not be written on behalf of the student. Furthermore, additional authors should not provide significant contributions in place of the student. This would essentially help to eliminate the 'empiricism provider' and 'one-trick pony' anti-patterns.

Finally, during the execution, the recommendations for the first steps are still valid. In addition, the following aspects should be considered:

- The supervisor should organize coaching events. Inviting several students to the same event would enable peer support, too. Remember to take holidays during the process. The related anti-patterns include the 'out-ofsteam' and 'performance anxiety' scenarios.

In the execution phase, it might also be a good idea to return to the role of the research plan. Finalization of the thesis involves intensive work. The candidate needs an opportunity to concentrate full-time on publishing research and writing the thesis. Public grants are easily available for students for fulltime research work in the finalization phase; we recommend using this opportunity. A good research plan and progress report help in getting positive results from the applications.

\section{RELATED WORK}

There is some existing research on the motivations and wellbeing of $\mathrm{PhD}$ students but most of that work does not focus on computer science or engineering students. In [11], del Carmen and Kollanus investigate the intrinsic and extrinsic motivations of $\mathrm{PhD}$ students. Most of our example antipatterns are not directly linked to either of these motivations, but the 'escape pod' can be seen an intrinsic - but negative motivation. The same article also recognized two European types of doctoral schools: traditional and structured. The industrial $\mathrm{PhD}$ option was not discussed in that research study but evidently the industrial $\mathrm{PhD}$ fits only in the more flexible traditional model. Furthermore, [11] lists five motivational drivers: academic career, professional development, career change, employment opportunity and personal fulfilment. Our findings are related to the second and fifth drivers. Howell
Smith et al. [14] also discuss three motivation-related misperceptions, but none of them, even the Nature of Work Misperceptions, is about how to conduct the actual doctoral studies and research.

In [14], Smith et al. investigate the motivations of engineering students and remind us that the majority of $\mathrm{PhDs}$ work in industry and they even recommend that graduate programmes should reach and recruit people with a practical interest in industry. However, they do not consider students who work in an industrial context during their $\mathrm{PhD}$ studies.

The various difficulties and issues faced in $\mathrm{PhD}$ studies are discussed in [6]. In that paper, the authors divide the difficulties into faculty- and student-related. Our anti-patterns are mainly student-related - except for the 'empiricism provider' which is often university-related. Many papers, for example [6] and [15], underline the important role of the supervisor and the link to a research group. This is strongly in line with our analysis, and we feel that these aspects need to be developed to better support industrial PhD students.

In general, we have found related topics and issues in previous research. However, the existing research focuses on full-time doctoral schools and not on students that have other significant responsibilities during their doctoral studies. However, the critical role of the supervisor and importance of the good link to the research community are considered important both in existing research and in our findings.

\section{CONCLUSIONS}

We have listed our recommendations in the Section IV.D partially embedded in the anti-patterns introduced (correcting actions), partially concluded at the end of the section. We do not return anymore to these. Industrial $\mathrm{PhD}$ students are in many ways different from their colleagues in universities. The motivational background of the students is different. While in universities the students' motivation comes from career needs (it is impossible to proceed without a doctoral degree), in industry the motivation is related - or at least should be - to personal ambitions and to the research topic. The organizational viewpoint is also different. While universities are rewarded for producing doctoral degrees, the energy that a $\mathrm{PhD}$ student in industry spends on doctoral studies does not necessarily support the business goals of the company. Industrial and pure-academic students are also different cases for the supervisor. An academic student is part of the research team and directly supports the research interests of the supervisor. On the other hand, the supervisor is responsible for the management and funding of the research. The benefits of industryacademia collaboration should motivate both companies and professors to support industrial doctoral students, but the issues reported in this paper need to be tackled.

In this paper we have discussed issues that according to our experience are specific to $\mathrm{PhD}$ students who work in industry while conducting their doctoral studies and research. We have documented several anti-patterns that we have seen in concrete cases. From these anti-patterns we have made a few recommendations that are mainly targeted at supervisors. Although our paper highlights the problems, we would nevertheless like to encourage professors, companies and students to take up this challenge since there is opportunity for research with real impact both in academia and industry. 


\section{REFERENCES}

[1] W. Basili, R.W. Selby, D.H. Hutchens, "Experimentation in Software Engineering", IEEE Transactions on Software Engineering, Vol. SE12, No.7, July 1986.

[2] B. Boehm, H.D. Rombach, M.V. Zelkowitz (eds.), "Foundations of Empirical Software Engineering - The Legacy of Victor R. Basili", Springer-Verlag. 2005, ISBN 3-540-24547-2.

[3] W.H. Brown, R.C. Malveau, H.W. McCormick, T.J. Mowbray, "AntiPatterns: refactoring software, architectures, and projects in crisis". John Wiley \& Sons, Inc.1998.

[4] G. Claxton G., Wise up, "The challenge of lifelong learning”. London: Bloomsbury. 1999.

[5] E. Gamma, R. Helm, R. Johnson, J. Vlissides, "Design patterns Elements of Reusable object-oriented software". Addison-Wesley. 1997, ISBN 0-201-63361-2.

[6] S.K. Gardner, "Student and faculty attributions of attrition in high and low-completing U.S. doctoral programs", Higher Education. Vol. 58, pp. 97-112. 2009

[7] H-M. Järvinen, T. Mikkonen, "Industrial impact on topics and types of Master's theses: Empirical study of software engineering theses made in 1990-2016”, In H-M. Järvinen, R. Clark (Eds.), Proceedings of SEFI 2016 Annual Conference European Society for Engineering Education SEFI. 2016.

[8] J. Järvinen, T. Huomo, T. Mikkonen, "Running software research programs: an agile approach", In 2017 IEEE/ACM 39th International Conference on Software Engineering Companion (ICSE-C), pp. 314 316, IEEE. 2017.
[9] E. Kasanen, K. Lukka, A. Siitonen, "The Constructive Approach in Management Accounting Research", Journal of Management Accounting Research, 5, pp. 243-264. 1993.

[10] T. Mikkonen, C. Lassenius, T. Männistö, M. Oivo, J. Järvinen, "Continuous and collaborative technology transfer: Software engineering research with real-time industry impact", Information and Software Technology, Vol. 95, March 2018, pp. 34-45.

[11] M. del Carmen Calatrava Moreno, S. Kollanus, "On the motivations to enroll in doctoral studies in Computer Science - A comparison of $\mathrm{PhD}$ program models", Proceedings of the 12th International Conference on Information Technology Based Higher Education and Training (ITHET), pp 1-8. 2013.

[12] K. Peffers, T. Tuunanen, M.A. Rothenberger, S. Chatterjee, "A Design Science Research Methodology for Information Systems Research", Journal of Management Information Systems, 24(3), 45-77. 2007-2008, doi:10.2753/MIS0742-1222240302

[13] A. Sandberg, L. Pareto, T. Arts, "Agile collaborative research: Action principles for industry-academia collaboration”, IEEE Software, 28(4), pp. 74-83. 2011.

[14] M.C.H. Smith, A.L. Garrett, E. Weissinger, E. and N. Chandra, "It's not what you think: A theory for understanding the lack of interest among domestic students in the engineering PhD," Proceedings of the Frontiers in Education Conference (FIE), Rapid City, South Dakota, USA, 12-15 Oct. 2011.

[15] J. Stubb, K. Pyhältö, and K. Lonka, "Balancing between inspiration and exhaustion? PhD students' experienced sociopsychological wellbeing”, Studies in Continuing Education, Vol. 33(1), pp. 33-50. 2011. 